\title{
Analysis of laser-melt pool-powder bed interaction during the selective laser melting of a stainless steel
}

\author{
Valérie Gunenthiram, Patrice Peyre, Matthieu Schneider, Morgan Dal, Frédéric Coste, \\ and Rémy Fabbro \\ PIMM Laboratory, UMR 8006 Arts et Métiers-CNRS-CNAM, 151 Bd de l'Hôpital, 75013 Paris, France
}

\begin{abstract}
The laser powder bed fusion (LPBF) or powder-bed additive layer manufacturing process is now recognized as a high-potential manufacturing process for complex metallic parts. However, many technical issues are still to overcome for making LPBF a fully viable manufacturing process. This is the case of surface finish and the systematic occurrence of porosities, which require postmachining steps. Up till now, the porosity origin remains unclear but is expected to be related to the stability of the process. As a LPBF part is made by the accumulation of hundreds of meters of small weld beads, it also appears to be important to understand all the phenomena that occur during the laser-powder-melt pool (MP) interaction for each single track. For this reason, in the first part of our study, using an instrumented LPBF setup and a fast camera analysis ( $>10000$ image/s), single tracks were fabricated and analyzed in real time and postmortem. Spatters ejections and powder denudation phenomena were observed together with variations of melt pool dimensions and meltpool instabilities. In turn, the physical origin of this powder denudation and the dynamics of the MP were investigated and discussed.
\end{abstract}

Key words: additive manufacturing, selective laser melting, powder bed fusion, spatters

\section{INTRODUCTION}

Laser powder bed fusion (LPBF) allows the fabrication of three-dimensional (3D) and physical models, parts and tools directly from computer-aided design (CAD) data using metal powders. The interaction between the laser and powder can be affected by heat, mass, and momentum transfer, all associated with the consequential problems of surface finish $(\mathrm{Ra}>10 \mu \mathrm{m}){ }^{1}$ pores, and thermal cracks. It is therefore of paramount importance to understand the interaction between the laser and powder, both to obtain the desired LPBF parts and to counteract these potential defects. Also, during a powder bed melting process, complex dynamic phenomena occur (spatter ejection, melt-pool (MP) instabilities...), which can have a direct influence on process optimization (Fig. 1).

In addition, a few researchers have investigated melt pool behavior in laser processing. Yadroitsev et al. ${ }^{2}$ studied the capillary instability of segmental cylinders and effects of the processing parameters such as the scanning speed and laser power on single tracks' formation. He found two instability zones: (1) at a low scanning speed where the track exhibits irregularities attributed to a capillary instability or Plateau-Rayleigh instability, (2) on the contrary, excessively high speed gives rise to the balling effect. Zhou et al. ${ }^{3}$ suggested that the formation of LPBF defects can be correlated to the melt pool dynamics, oscillations, and PlateauRayleigh instability. The melt pool is forced to oscillate by disturbances from the thermocapillary convection, pulsed laser recoil force, and the shear stress in the gas-melt interface. Kruth et al. ${ }^{4}$ observed the influence of high thermal gradients and the vaporization effect on the balling phenomena. Here, the low speed gives rise to the balling effect, whereas the high speed generates nonconnected meltpools. Yadroitsev and Smurov 5 studied the impact of the hatch distance and powder layer thickness on the morphology of the first layer and the surface structure of thin walls. $\mathrm{He}$ also highlighted a powder denudation effect near the melt-pool after laser scanning. In turn, the hatch value should depend on the length of denudation and the width of the track. Recently, Matthews $e t ~ a l .{ }^{6}$ investigated extensively the denudation phenomenon of titanium alloy and steel alloy powders under varying laser conditions and ambient gas pressures. According to them, the denuding can mostly be due to intense metallic vaporization phenomena near the laser spot, provoking entrainment of powder particles. Liu et $a l .^{7}$ studied dynamic processes of spatter formation for different energy inputs by using a high-speed camera. He found that a higher energy input intensifies the spatter behavior and that the average particle size is almost three times that of the powder particle. Qiu et al. ${ }^{8}$ observed that the velocity of scattered melt particles was found to generally increase with the increase in the laser scanning speed. Alongside the melt splashing there is always a blurred tail following the moving melt flow, which is suspected to be due to material evaporation. All these investigations provide interesting data on physical phenomena occurring during LPBF, but also exhibit contradictions, for instance, the difference between the balling and Rayleigh-like instabilities.

This study aims to provide a new insight on melt pool and powder behavior during laser-matter interactions, thereby offering suggestions on the choice of effective process parameters. 


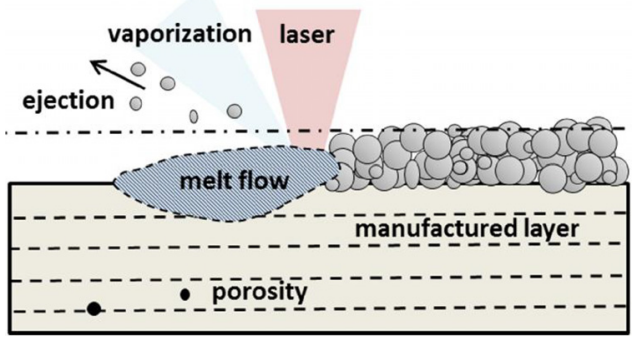

FIG. 1. The powder bed fusion process.

\section{EXPERIMENTAL TECHNIQUES AND MATERIALS}

\section{A. LPBF experiments}

The experiments were carried out on an SLM (selective laser melting) Solution $125^{\mathrm{HL}} \mathrm{GmbH}$ machine, equipped with a 400 W IPG fiber laser (ytterbium-doped, continuous mode, wavelength $1070 \mathrm{~nm}$ ). The building envelope is $125 \times 125 \times 125 \mathrm{~mm}^{3}$. The scanning system used was a dual axis mirror positioning system and a galvanometer optical scanner, which directs the laser beam in the $X$ - and $Y$-axes. Focusing optics employed a f-theta lens, which produces a focused beam diameter of approximately $70 \mu \mathrm{m}$ with a $\mathrm{TEM}_{00}$ distribution. LPBF processing was carried out in an $\mathrm{Ar}$ atmosphere with a maximum of $0.05 \% \mathrm{O}_{2}$. The main technical parameters of the machine are shown in Table I.

\section{B. Experimental setup}

Due to the complexity to put diagnostics inside a LPBF chamber, an instrumented setup was used for the high-speed analysis of laser-powder-melt-pool interactions (Fig. 2). The main differences between instrumented setup and LPBF machine melting conditions were as follows (Table I): the beam diameter, the Ar shielding (global in the machine, local in the setup), and the layer thickness. During single track experiments, a predeposited (using a razor edge) powder bed is moved below the laser with a high speed $(x, y)$ table. Simultaneously, a high-speed camera (SA2 Photron with a C-Mos sensor) positioned laterally synchronized with a dedicated lighting system, was used to observe the melt pool behavior. Additionally, reflectivity measurements were carried out with the use of an Ulbricht Sphere.

\section{Postmortem analysis of LPBF samples}

LPBF beads were analyzed by optical microscopy after a sequence of cutting-mounting and polishing metallographic

TABLE I. Comparison of process parameters for industrial SLM machine and instrumented setup.

\begin{tabular}{lcc}
\hline \hline Item & Setup & Machine \\
\hline Wavelength & $1075 \mathrm{~nm}$ & $1070 \mathrm{~nm}$ \\
Focus beam & $200 \mu \mathrm{m}$ & $70 \mu \mathrm{m}$ \\
diameter & (top-hat) & $($ Gaussian $)$ \\
Scan speed V & $0.33-0.75 \mathrm{~m} / \mathrm{s}$ & $0.75 \mathrm{~m} / \mathrm{s}$ \\
Laser Power P & $150-1600 \mathrm{~W}$ & $175 \mathrm{~W}$ \\
Layer thickness & $65 \mu \mathrm{m}$ & $30 \mu \mathrm{m}$ \\
\hline \hline
\end{tabular}

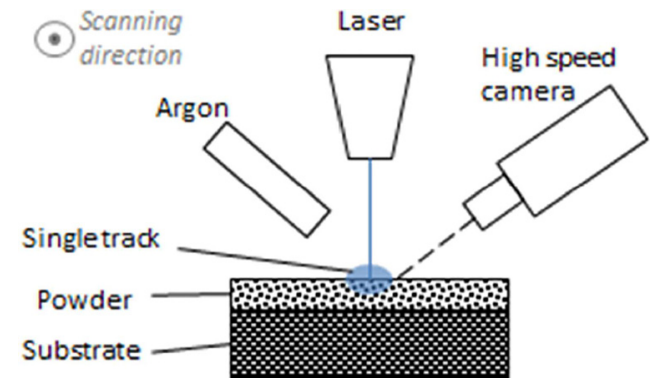

FIG. 2. Instrumented LBPF setup.

preparation. To analyze the surface of LPBF samples, of single tracks and spatter morphology at a higher magnification, a Hitachi 8400 scanning electron microscope (SEM) was used. The morphology of LPBF surfaces and powder bed environment before and after single tracks was analyzed using 3D profilometers (Dektak Stylus, with contact and Alicona Infinite Focus SL optical setup without contact).

\section{Material}

The material used in this study was 316L stainless steel spherical powder, as shown in Fig. 3. An average grain diameter of $d 50=21 \mu \mathrm{m}$ was used. The chemical compositions of the powdered material are shown in Table II.

\section{RESULTS}

\section{A. Reflectivity measurements}

During laser-powder bed interactions, a part $(R)$ of the laser radiation is lost, reflected, and the rest of the laser light
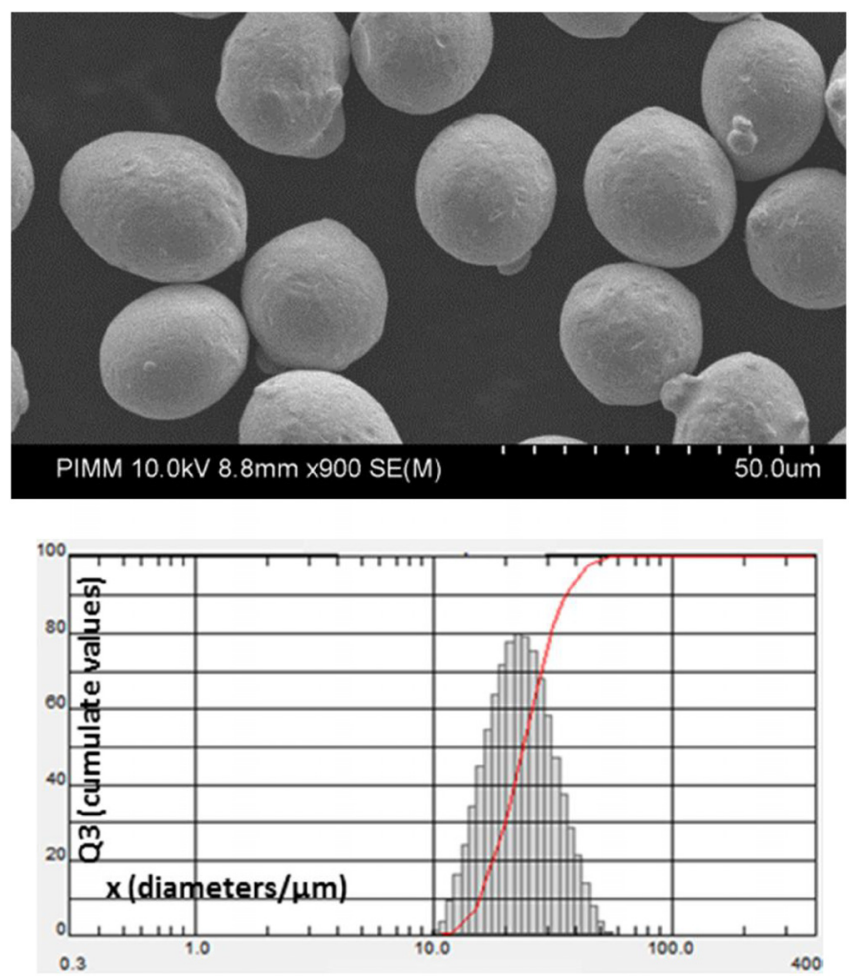

FIG. 3. 316L stainless steel powder, (a) SEM image, and (b) particle distribution. 
TABLE II. 316L stainless steel powder chemical compositions (mass fraction \%).

\begin{tabular}{lccccccc}
\hline \hline $\mathrm{C}$ & $\mathrm{Cr}$ & $\mathrm{Ni}$ & $\mathrm{Mo}$ & $\mathrm{Si}$ & $\mathrm{Mn}$ & $\mathrm{O}$ & $\mathrm{Fe}$ \\
\hline 0.03 & 17.53 & 12.06 & 2.16 & 0.86 & 0.38 & 0.13 & $\mathrm{Bal}$ \\
\hline \hline
\end{tabular}

is absorbed $(A)$ by the powder layer. In order to measure the reflectivity $R$, an Ulbricht sphere is used, as shown in Fig. 4. A substrate covered with a powder bed layer is introduced inside the sphere, previously coated with $\mathrm{Ba}_{2} \mathrm{SO}_{4}$ to favor reflectance, and with Ar shielding. A laser irradiation is then applied on the powder bed during a time $t_{0}$, during which the reflected part of the beam part is distributed throughout the inner walls of the sphere and detected by a photodiode. A voltage versus time signal $V(t)$ is then recorded with the amplitude proportional to the reflected energy. The reflectivity is obtained by considering the ratio between the voltage amplitude recorded on the powder bed and the reference voltage (obtained without sample in the sphere). Figure 5 shows the reflectivity evolution during the static melting, at $P=320 \mathrm{~W}$ laser power and $t_{0}=10 \mathrm{~ms}$ irradiation time of a $90 \mu \mathrm{m}$-thick powder layer thickness. During melting, the reflectivity of the powder-bed increases (from 0.24 to 0.38 ), whereas the reflectivity of the bare substrate tends to decrease (0.58 to 0.42). Moreover, a clear difference is evidenced between the solid substrate $(R=0.58)$ and the powder bed surface $(R=0.24)$. These observations, confirmed for other laser irradiances, suggest that (1) multireflection phenomena combined to higher absorptivity due to higher roughness have occurred inside the powder bed and (2) the laser absorptivity during LPBF on $316 \mathrm{~L}$ steel, which mostly occurs at the liquid state is comprised between $(1-R)=0.58$ and 0.62 .

\section{B. Analysis of LPBF melt-pools}

A final LPBF part, carried out in industrial machines, is obtained by the accumulation of hundreds of meters of overlapped single tracks. To provide a better understanding of the local interaction, a parametric investigation of single tracks was carried out by tuning $P$ and $V$ values, and considering the melting of a powder layer predeposited on a stainless steel substrate. Figure 6 shows postmortem SEM

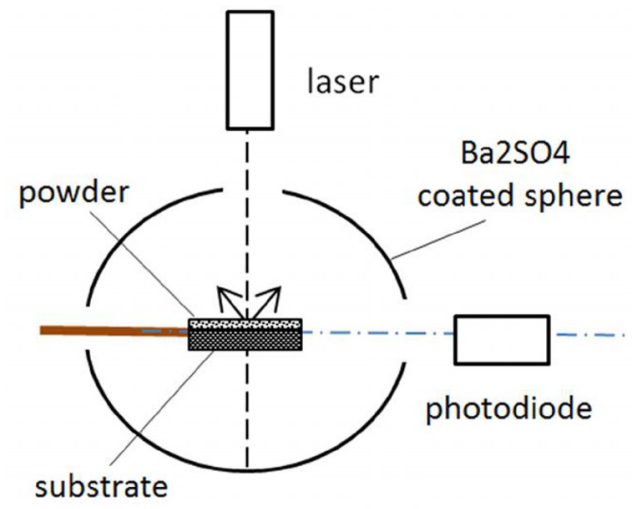

FIG. 4. Basic principle of Ulbricht sphere.

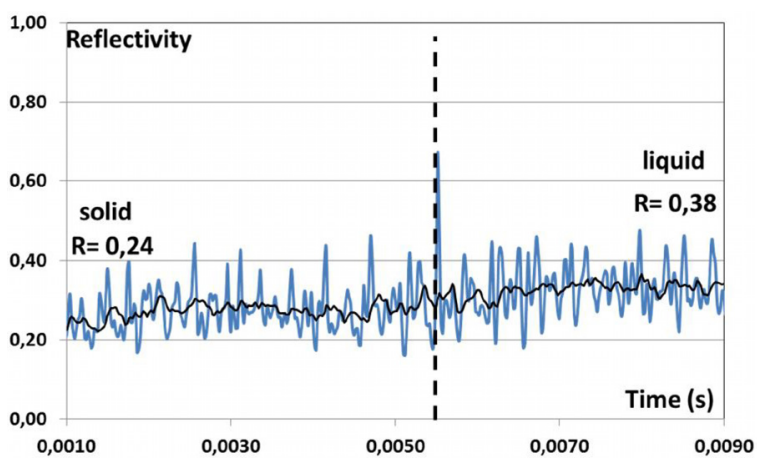

FIG. 5. Reflectivity measurements versus time. An increase in the material's reflectivity is evidenced at the solid-liquid transition.

analysis of single tracks for different lasers powers (160, $260,360,400,450$, and $680 \mathrm{~W})$, scanning speed $(0.3,0.4$, 0.6 , and $0.75 \mathrm{~m} / \mathrm{s}$ ), and a focus beam diameter of $200 \mu \mathrm{m}$. It can be evidenced that the low laser power and high speed (for example, $P=159 \mathrm{~W}-V=0.6 \mathrm{~m} / \mathrm{s}$ ) lead to the so-called balling phenomena whereas the high laser power and low speeds generate homogeneous track. In this case, the balling phenomenon is clearly caused by a lack of dilution with the substrate, resulting in a melt pool spheroidization to minimize free energy. Figure 7 shows images captured from a high speed video of LPBF melt-pools recorded at $12500 \mathrm{fr} / \mathrm{s}$ at a constant velocity of $0.33 \mathrm{~m} / \mathrm{s}$ and for two different laser powers of 160 and $660 \mathrm{~W}$. Such video analyses provide us with several data: (1) The melt pool dimensions which are obtained either on videos (MP length $L$ ) or from SEM images (examples of MP width 1: Fig. 8) and (2) the MP dynamics, including particle ejections and possible MP instabilities. Figure 9 depicts the MP dimensions and MP size ratio $L / l$ versus energy density $E\left(\mathrm{~J} / \mathrm{m}^{2}\right)=\left(D_{\text {laser }}(\mathrm{m}) / V(\mathrm{~m} / \mathrm{s})\right)$ $\cdot\left(P(\mathrm{~W}) / S\left(\mathrm{~m}^{2}\right)\right)$. These results globally show an important increase in MP length with the energy density, and a rather

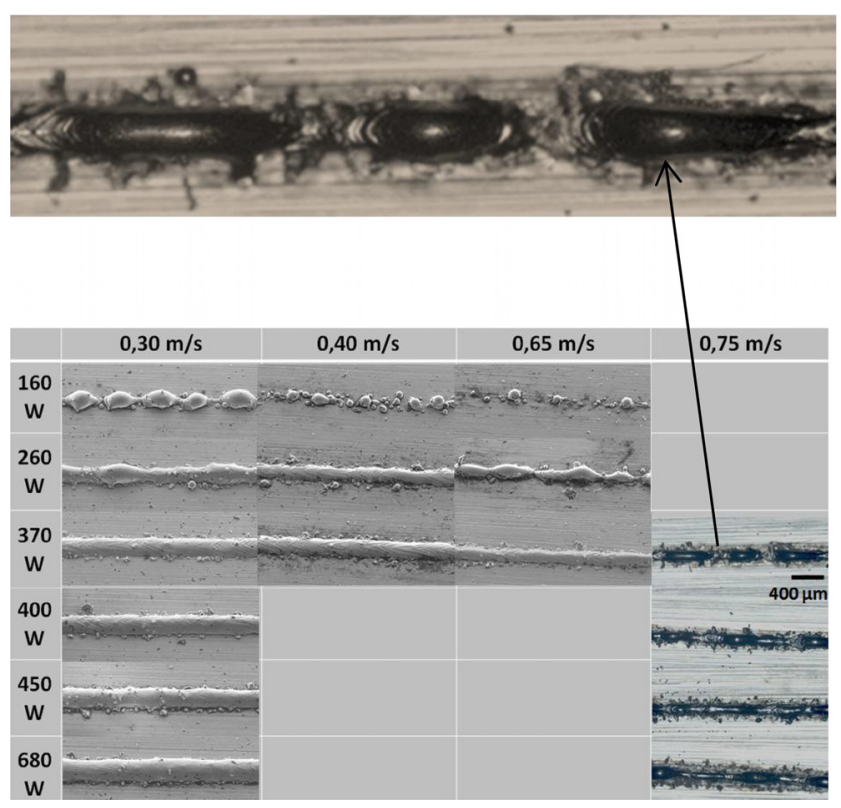

FIG. 6. Single track processing map for the first LPBF layer at different velocities and laser powers. 


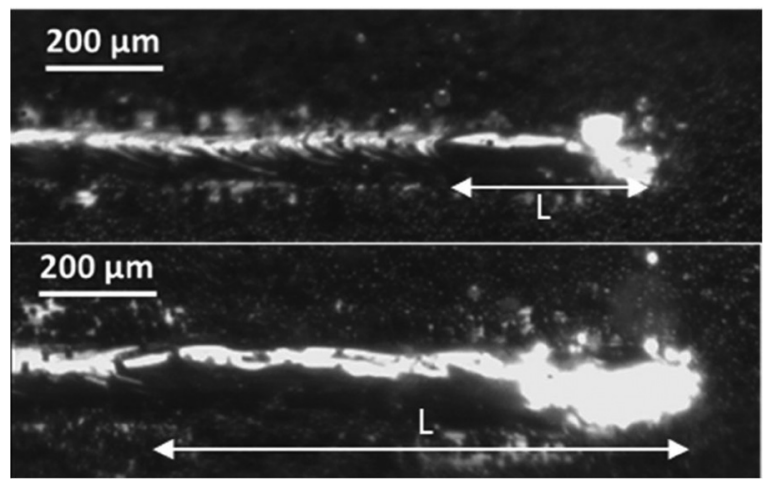

FIG. 7. High speed images of LPBF melt-pools at a constant velocity $0.33 \mathrm{~m} / \mathrm{s}$ and different laser powers: (a) $160 \mathrm{~W}$ and (b) $660 \mathrm{~W}$.

constant MP width, near the initial laser spot-diameter (Fig. 8). More interestingly, a transition between a stable meltpool and a nonstable melt-pool (called humping transition) is shown above a $L / l$ ratio above $L / l=5$. This humping effect widely investigated by Seiler et $a l .^{9}$ in the case of laser welding can be mostly explained by surface tension effects combined with backward fluid flow which is usually promoted by recoil vapor pressure applied on the MP.

Figure 10 shows single tracks images taken using a high speed camera at $0.75 \mathrm{~m} / \mathrm{s}$ and four laser powers $(520,720$, 920 , and $1220 \mathrm{~W}$ ). These pictures confirm the occurrence of a periodic humping instability at a high velocity whatever the laser power. Such an effect is accentuated by the high ability of stainless steels to hump. ${ }^{9,10}$ This instability is usually attributed to Plateau-Rayleigh or Rayleigh-Taylor (RT) capillary instability. RT instability occurs when an infinite fluid column is subjected to periodic instabilities of period $2 \pi R$ with column radius $\mathrm{R}$. It is favored by (1) thin melt pools with high surface tension coefficients, (2) small local curvature radius $R$ or melt-pool widths, ${ }^{9}$ and (3) melt pools having a high length over width ratio $(L>2 \pi R$ (Ref. 4$)$ ). Such $L / l$ ratios $(\approx 2 \pi)$ are nearly the same than those obtained experimentally $(L / l=5$ in Fig. 9), which tend to confirm afterward the assumption of a RT effect. Figure 11 depicts cross-sectional images of single LPBF beads obtained by optical microscopy for two velocities $(0.30$ and $0.75 \mathrm{~m} / \mathrm{s})$ and a range of laser powers. At $0.3 \mathrm{~m} / \mathrm{s}$, these results logically show that the melt pool penetration depth in the substrate increases with the laser power. At $0.75 \mathrm{~m} / \mathrm{s}$, a much lower dilution is shown. An interesting point to notice is that

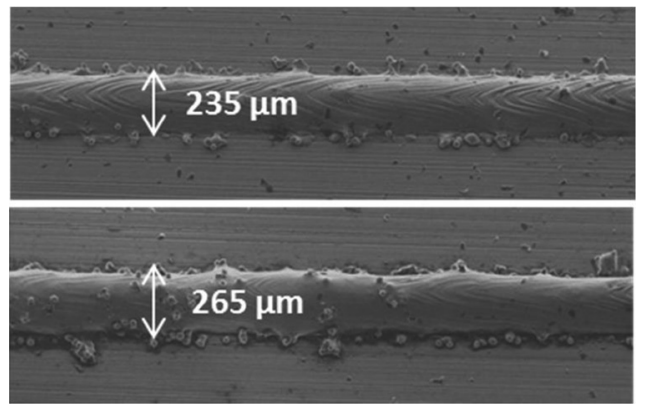

FIG. 8. SEM analysis of single LPBF beads at $0.30 \mathrm{~m} / \mathrm{s}$ : (a) $360 \mathrm{~W}$ and (b) $660 \mathrm{~W}$. A very tiny increase in the MP width is evidenced.

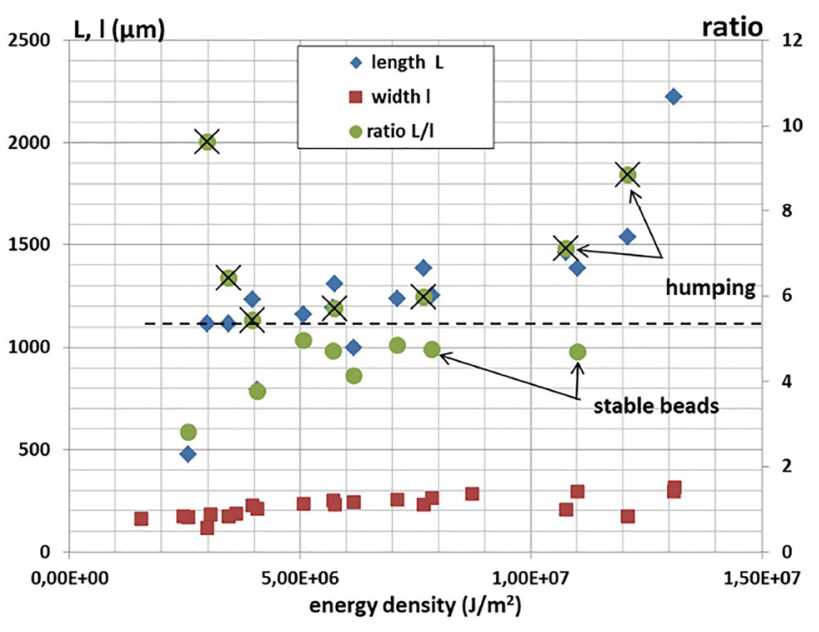

FIG. 9. Melt-pool dimensions and ratios $(L / l)$ versus energy density: a transition is shown (dotted line) between stable and nonstable beads.

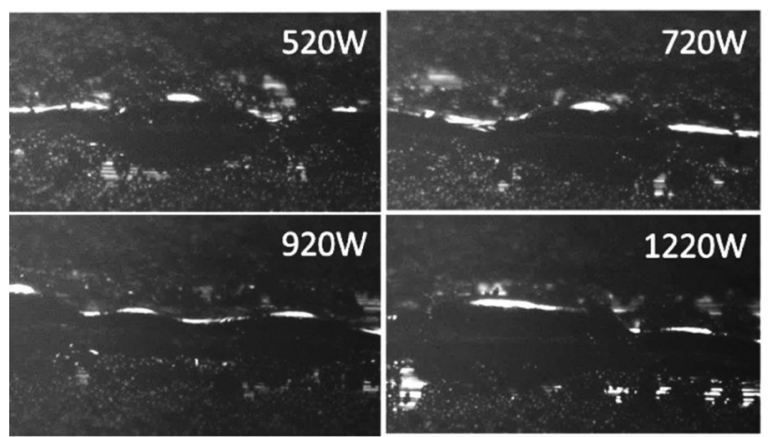

FIG. 10. Melt-pool instabilities (instrumented setup)—single track at $0.75 \mathrm{~m} / \mathrm{s}$ and different laser powers $(520,720,920$, and $1220 \mathrm{~W})$.

a)

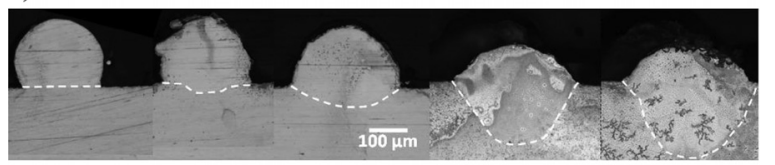

b)

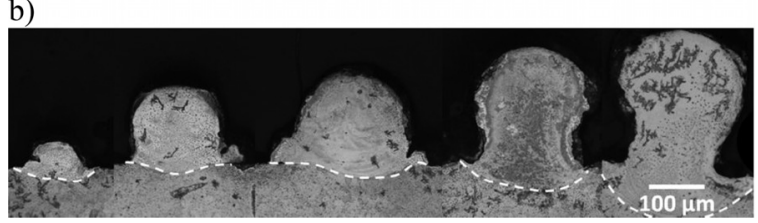

FIG. 11. Cross-sectional analysis of single LPBF beads (optical micros-

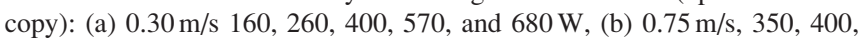
470,900 , and $1430 \mathrm{~W}$. A humping effect is shown at a high velocity and high power.

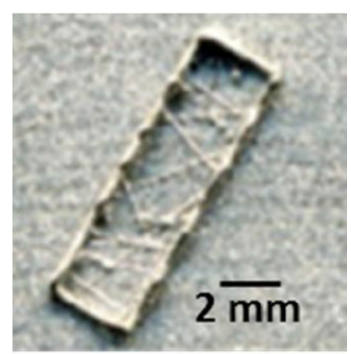

FIG. 12. MP instabilities observed on a LPBF machine-wall $10 \times 3 \times 1 \mathrm{~mm}$ $(0.75 \mathrm{~m} / \mathrm{s}$ and $175 \mathrm{~W})$. 


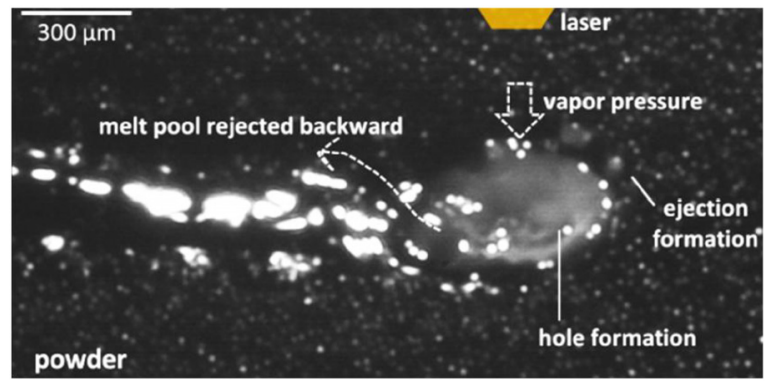

FIG. 13. Melt pool behavior analysis (using a high speed camera) during a single LPBF track at $0.75 \mathrm{~m} / \mathrm{s}$ and $1270 \mathrm{~W}$.

at a high laser power (900 and $1430 \mathrm{~W}$ ) and a high scanning speed $(0.75 \mathrm{~m} / \mathrm{s})$, the MP height tends to increase above the initial surface level simultaneously with the formation of a lateral shrinking effect attributed to surface tension stresses $F=\gamma / R$. Such an effect is promoted by large $L / l$ values as shown in Fig. 9.

Previous observations suggest that at a high velocity $(0.75 \mathrm{~m} / \mathrm{s})$, a melt pool instability occurs when $P$ increases (for large $L / l$ ratios). Similarly, a LPBF wall processed by a LPBF machine at $0.75 \mathrm{~m} / \mathrm{s}$ also presents periodic ripples as shown in Fig. 12.

To further understand the physical mechanisms involved, Fig. 13 depicts a high speed camera image during laser melting at $0.75 \mathrm{~m} / \mathrm{s}$ and $1270 \mathrm{~W}$. This image shows (1) the spatter formation initiated at the melt pool front, (2) the formation of a vertical depression on the MP due to vapor formation that pushes the melt pool, (3) a liquid flow rejected backward at high velocity and above the starting surface. This suggests the first stage of a keyhole initiation, which can be considered as an additional humping source. Indeed, the key-hole promotes backward fluid flow, which tends to increase the $L / l$ ratio.

\section{Analysis of metal ejections}

Large spatter particles (such as 20-100 $\mu$ m molten metal droplets) coming from laser-powder-melt-pool interactions (Fig. 13) can act as inclusions in the final LPBF parts, thus modifying the resulting roughness and affecting the mechanical properties. Therefore, the analysis and understanding of spatter formation is of highest importance to optimize the process parameters. Using high speed camera videos (12 500 $\mathrm{fr} / \mathrm{s}$ ), the formation of ejections was mostly found between the front of the melt-pool and the nonmelted powder bed

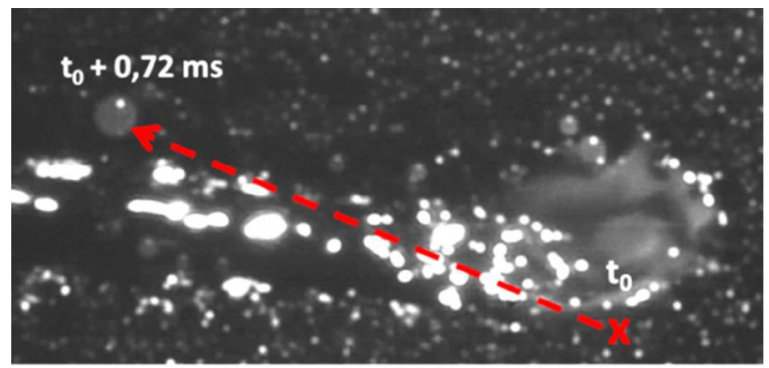

FIG. 14. Trajectory of molten particles at the rear of a LPBF melt-pool at $0.75 \mathrm{~m} / \mathrm{s}$ and $1270 \mathrm{~W}$. a)

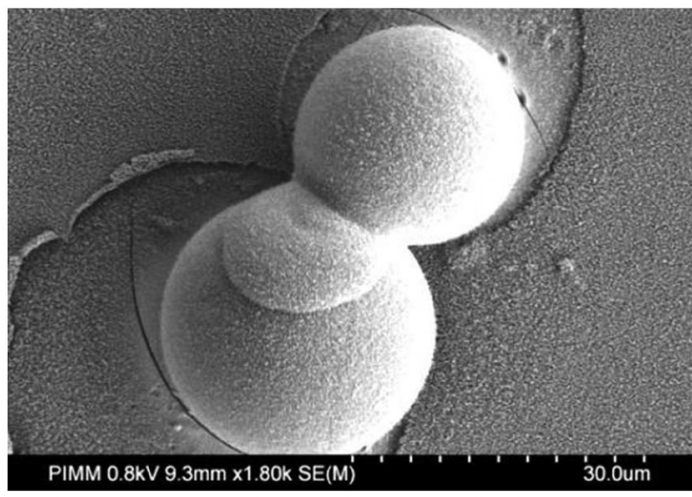

b)

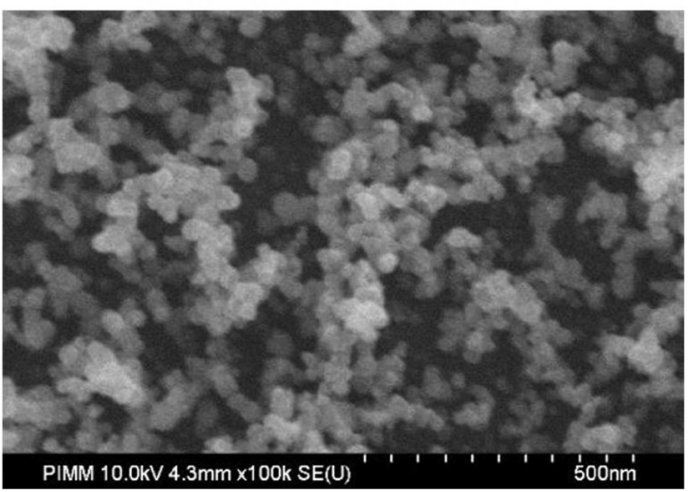

FIG. 15. SEM analysis of ejections: (a) macrodroplets covered by nanoparticles and (b) nanocondensates- $(0.3 \mathrm{~m} / \mathrm{s}-320 \mathrm{~W})$.

(Fig. 13). A high speed video analysis of the trajectory of spatters (Fig. 14) indicates a very wide range of angles versus the normal direction, and spatter velocities around $V_{\text {spatter }} \approx 0.3-0.7 \mathrm{~m} / \mathrm{s}$.

On the instrumented setup, a glass slide was placed $3 \mathrm{~mm}$ above the powder bed to collect the splashing of molten particles. ${ }^{11}$ Single track have been realized at $0.3 \mathrm{~m} / \mathrm{s}$ and different laser powers $(320,720 \mathrm{~W})$. The SEM analysis of glass slide reveals a combination of macrodroplets $(\max \approx 30 \mu \mathrm{m})$ and nanoparticles (average $\approx 30 \mathrm{~nm}$ ) (Fig. 15). These nanoparticles are attributed to the condensation of a laser-induced metal vapor, and further analysis should confirm whether they are composed or metal or oxide.

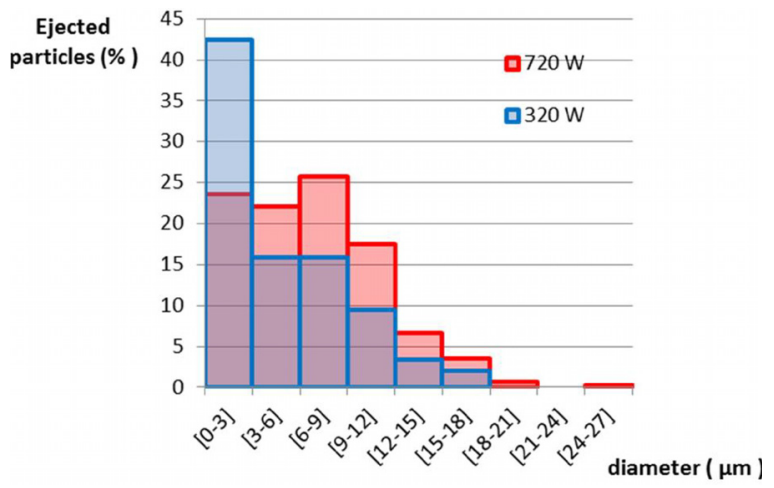

FIG. 16. Histogram of ejections at $0.3 \mathrm{~m} / \mathrm{s}$. 


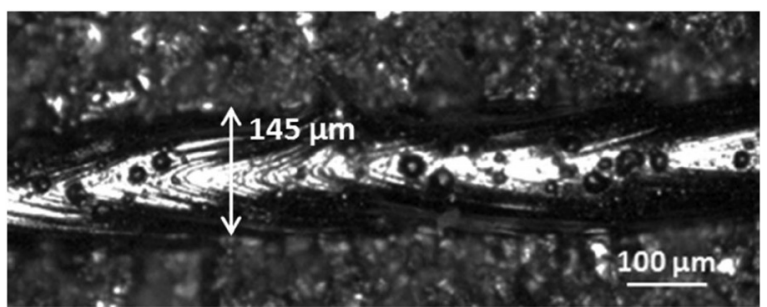

FIG. 17. Single track (LPBF machine) $-0.75 \mathrm{~m} / \mathrm{s}-200 \mathrm{~W}$.

After image treatment using ImageJ software, the microscopic analysis of glass gives (1) the number of ejections for a given surface and (2) the size distribution histogram (Fig. 16). The average spatter diameter is shown to be close to $10 \mu \mathrm{m}$. However, all the ejected particles have not been taken into account, especially those (the larger and heavier ones shown on videos) that have not reached $3 \mathrm{~mm}$ height. At a low laser power $(320 \mathrm{~W})$, the ejected particles are mostly small $(<3 \mu \mathrm{m})$. When the laser power increases $(720 \mathrm{~W})$, larger particles are also shown (Fig. 16), and the amount of ejected particles increases (320 W:297 particles/ $720 \mathrm{~W}: 453$ particles), the result which is confirmed by the video analysis.

\section{Analysis of powder denudations}

The optimization of the hatch distance permits the cohesion between single tracks in a LPBF part. However, on most of usual LPBF experimental conditions, very low overlaps are considered between subsequent tracks. For instance, a typical $120 \mu \mathrm{m}$ hatch distance is used, for bead widths near $145 \mu \mathrm{m}$ (Fig. 17). One of the possible reasons for this is the occurrence of denudation zones near the melt-pool, already mentioned by Yadroitsev and Smurov et al., ${ }^{5}$ but never
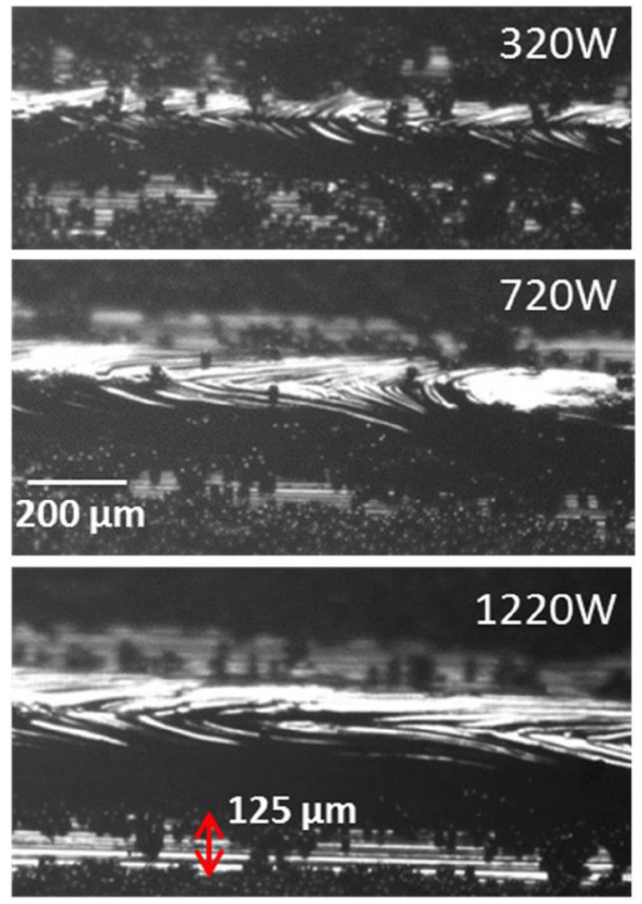

FIG. 18. Denudation of powder bed versus laser parameters-OM analysis of bead and powder bed surfaces at $0.3 \mathrm{~m} / \mathrm{s}$.

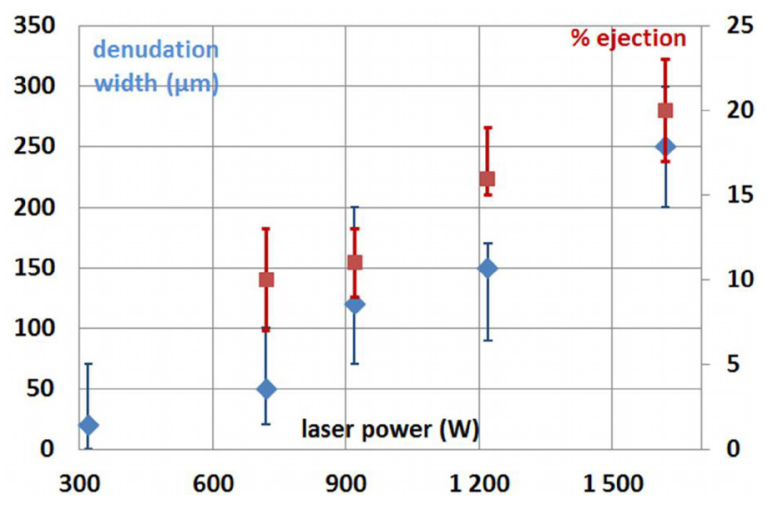

FIG. 19. Denudation width and $\%$ ejection versus laser power $(V=0.3 \mathrm{~m} / \mathrm{s})$.

investigated extensively so far except in a recent work by Matthews. ${ }^{6}$ Such clearing zones have been considered to occur, thanks to the entrainment of powder particles in a shear flow of gas coming from vaporization near the laser heat zone, and tend to increase with the laser power.

To confirm these recent data, the analysis of powder denudations has been realized on single tracks for different velocities and laser powers. It appears clearly on high speed videos that particles are attracted toward the melt-pool at an average velocity of $0.4 \mathrm{~m} / \mathrm{s}$ constant with laser power. The powder denudation is less visible at $0.75 \mathrm{~m} / \mathrm{s}$ than at $0.3 \mathrm{~m} / \mathrm{s}$, whereas for high laser powers, the powder denudation is clearly shown in Fig. 18. Figure 19 shows that the denudation width increases with the laser power realized at $0.33 \mathrm{~m} /$ s. The humping instability at $0.75 \mathrm{~m} / \mathrm{s}$ also generates inhomogeneity of the denudation zone as shown in Fig. 10. Using 3D profilometer without contact, a material balance area has been carried out, comparing the final solidified bead volume $\left(V_{\mathrm{sb}}\right)$ and the initial powder volume $\left(V_{\mathrm{IP}}\right)$ (Fig. 20). Preliminary calculations show that part of the powder was directly molten or attracted into the track whereas a nonnegligible part $(\approx 15 \%)$ was ejected into spatters or condensates (Fig. 19). The influence of surface roughness on powder denudation was also briefly addressed, by comparing a sand-blasted substrate $(\mathrm{Ra} \approx 2 \mu \mathrm{m})$ to a ground surface ( $\mathrm{Ra}$ $\approx 0.2 \mu \mathrm{m}$ ) in order to consider surface roughness nearly similar to those achieved during LPBF. Results indicate nearly similar denudation zones that should be confirmed in a next step for larger experimental conditions.

\section{DISCUSSION}

This paper focusses on all the physical phenomena involved during laser-powder-melt pool interactions. This interaction was carried out considering single tracks and using a high speed camera and postmortem characterization of LPBF beads as a function of $(P, V)$. Three aspects were studied in more detail in this paper: (1) the MP instabilities, (2) the formation of MP ejections and spatters, and (3) the powder denudation phenomena.

1. From our experimental data, a $(P, V)$ process map was established to discriminate two kinds of instabilities (balling or humping) versus stable MP behavior (Fig. 21). At a very low laser power, the fusion of the substrate is too 
a)
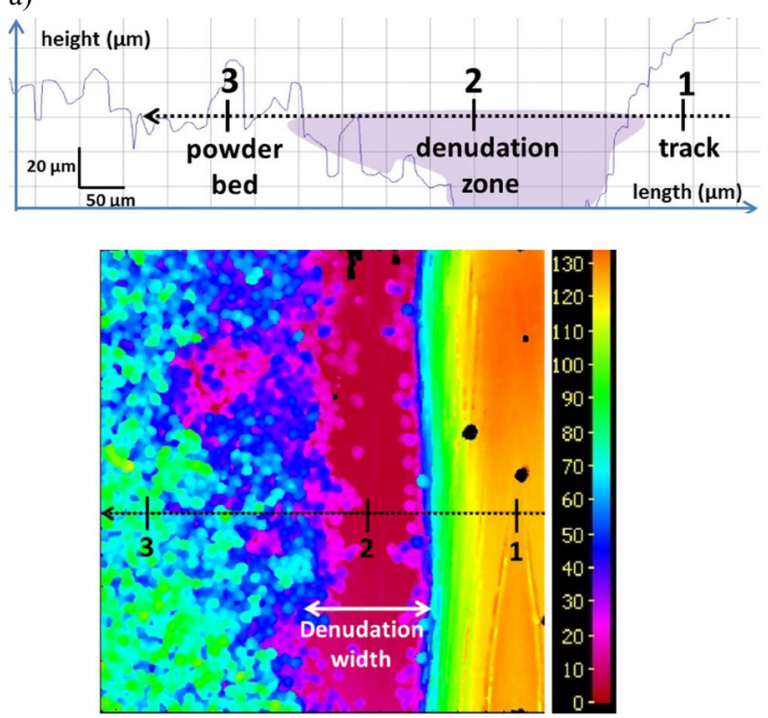

b)

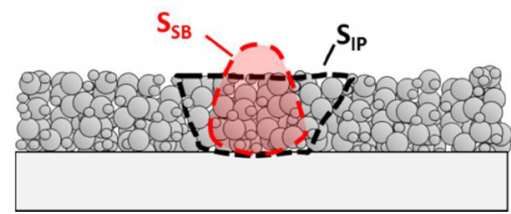

FIG. 20. (a) Powder denudation analysis (3D-profilometry without contact) — bead and powder bed surfaces at $0.3 \mathrm{~m} / \mathrm{s}$ and 1220. (b) Ejections calculation principle comparing the final solidified bead volume $\left(V_{\mathrm{sb}}\right)$ and the initial powder volume $\left(V_{\mathrm{IP}}\right)$.

limited to anchor the fused powder bed, and results in the balling effect. At a high velocity (favoring thin meltpools) and a high laser power (promoting elongated meltpools), the MP become unstable, mainly due to the formation of a vapor recoil pressure applied vertically on the laser-melt-pool interaction zone, which tends to reject the melt-pool backward, and above the initial surface, thus increasing its free surface. In turn, lateral surface tensions applied on the thin melt-pool flow provoke a periodic shrinking effect, well known as a humping phenomenon in laser welding. ${ }^{9}$ In all the experiments presented here, the formation of humping instabilities was systematically linked to recoil pressure and melt-pool vertical deformation, suggesting that LPBF melting conditions were near to the conditions for a keyhole initiation. Such assumptions

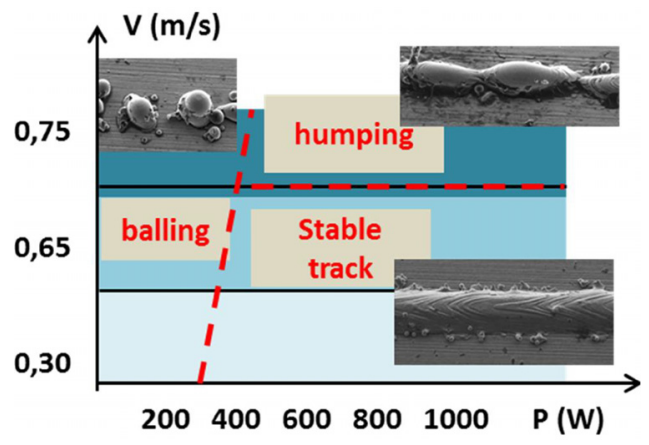

FIG. 21. LPBF process map indicating the zones of instabilities. are confirmed by cross-sectional analysis of beads (Fig. 11). These MP fluctuations were attributed to a Rayleighlike instability (Fig. 10), and confirmed by the MP ratio $(L /$ l) threshold, which was close to $L / l \approx 2 \pi$.

2 . The microscopic observation of spatters reveals a combination of macrodroplets $(10-30 \mu \mathrm{m})$ and nanoparticles $(30 \mathrm{~nm})$, with an increase in the spatter density for higher laser powers. High speed videos also indicate that the formation and backward ejection of large melt-pool droplets $(>50 \mu \mathrm{m})$ mostly initiating at the front edge of the MP near the powder bed, with velocities close to the scanning velocity. However, such large droplets could not be collected and analyzed on SEM, due to too-low kinetic energies (low velocities) of large spatters. Such large particles are the most deleterious ones for LPBF process, because they are suspected to provoke roughness increases and metallurgical inclusions.

3. The powder denudation effect is clearly evidenced not only on the final powder beds (Fig. 18) but also on high speed videos. Such videos clearly reveal a lateral powder flow toward the melt-pool, which seems to be restricted to the hotter MP zone coincident to a vertical vapor flow. ${ }^{12}$ Consequently, and in full agreement with Ref. 6, it can be assumed that the inward motion of powder particles toward the MP is directly provoked by the vapor flow. Such a vapor flow plume and the associated local shear tends to oscillate between a normal direction and a $30^{\circ}$ rear inclination (Fig. 22), whose effect can also provoke fluctuations in the attraction of particles and in the resulting denudation zone width. Additional denudation effects are also visible in terms of capillary-driven particle flow toward the MP. However, this phenomenon is restricted to a thin width in close vicinity with the MP edge.

Considering a given powder bed area before laser melting, it was also assumed that part of the powder was directly molten or attracted into the track whereas another fraction was ejected into spatters or condensates, especially for high laser powers. This allowed us estimating the fraction of

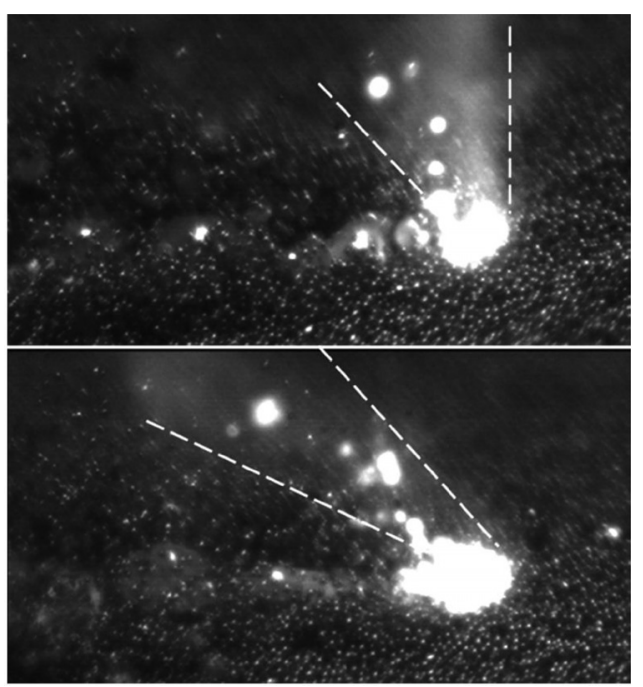

FIG. 22. High speed imaging of the vapor flow fluctuations at $0.33 \mathrm{~m} /$ s-320 W. 
particle ejection by comparing the final bead volume, with the initial powder bed volume (assuming a powder bed compactness of $\varepsilon=0.6$ ). Relatively high fractions of ejections are obtained (between $10 \%$ and 20\%), which confirm that the powder bed melting is unstable for the current process parameters considered here. Such a result should help to reconsider process parameters usually carried out in LPBF processes, and especially those provoking near key-hole melting conditions, and severe vaporizations.

\section{CONCLUSION}

This paper has presented a series of original experiments where various physical phenomena involved during the powder bed laser fusion have been analyzed and discussed. This includes (1) dynamic instabilities (balling, humping) of the melt-pool, (2) microparticles and macrospatters formation and ejection, and (3) powder denudation effects surrounding the tracks. Using a high speed video analysis and postmortem observation of beads and powder beds, it was shown that vaporization effects located near the laser-melt-pool interaction zone are the main driving force for most of these phenomena and, to some extent, provoke a destabilization of the global process. Such destabilization plays an important and constraining role in the resulting process optimization (selection of hatch distance, strategy), and final metallurgical or topographical properties of parts.

Future work should focus on even more detailed description of the metallic vapor formation, and on possible experimental methods to limit its deleterious effects.
${ }^{1}$ Wohlers annual report on 3D printing and additive manufacturing state of the industry, Technical Report No. 23, Wohlers Associate (2014).

${ }^{2}$ I. Yadroitsev, A. Gusarov, I. Yadroitsava, and I. Smurov, "Single track formation in selective laser melting of metal powders," J. Mater. Process. Technol. 210, 1624-1631 (2010).

${ }^{3}$ X. Zhou, X. Liu, D. Zhang, D. Shen, and W. Liu, "Balling phenomena in selective laser melted tungsten," Acta Mater. 98, 1-16 (2015).

${ }^{4}$ J. P. Kruth, L. Froyen, J. Van Vaerenbergh, P. Mercelis, M. Rombouts, and B. Lauwers, "Selective laser melting of iron-based powder," J. Mater. Process. Technol. 149, 616-622 (2004).

${ }^{5}$ I. Yadroitsev and I. Smurov, "Surface morphology in selective laser melting of metal powders," Phys. Proc. 12, 264-270 (2011).

${ }^{6}$ M. J. Matthews, G. Guss, S. A. Khairallah, A. M. Rubenchik, P. J. Depond, and W. E. King, "Denudation of metal powder layers in laser powder bed fusion, processes," Acta Mater. 114, 33-42 (2016).

${ }^{7}$ Y. Liu, Y. Yang, S. Mai, D. Wang, and C. Song, "Investigation into spatter behavior during selective laser melting of AISI 316L stainless steel powder," Mater. Des. 87, 797-806 (2015).

${ }^{8}$ C. Qiu, C. Panwisawas, M. Ward, H. C. Basoalto, J. W. Brooks, and M. M. Attallah, "On the role of melt flow into the surface structure and porosity development during selective laser melting," Acta Mater. 96, 72-79 (2015).

${ }^{9}$ M. Seiler, A. Patschger, and J. Bliedtner, "Investigations of welding instabilities and weld seam formation during laser microwelding of ultrathin metal sheets," J. Laser Appl. 28, 022417 (2016).

${ }^{10} \mathrm{P}$. S. Wei, The Physics of Weld Bead Defects, Chapter 16 of welding processes, edited by R. Kovacevic (Intech Publication, 2012).

${ }^{11}$ A. Masmoudi, "Modélisation et développement expérimental du procédé de fabrication sélective par fusion laser d'un lit de poudre métallique Influence de la pression atmosphérique," Ph.D. thesis, University of Belfort-Montbeliard, France, 2016, pp. 70-82.

${ }^{12} \mathrm{~A}$. Masmoudi, R. Bolot, and C. Coddet, "Investigation of the laser-powder-atmosphere interaction zone during the selective laser melting process," J. Mater. Process. Technol. 225, 122-132 (2015). 